\title{
BMI open Hypertension prevalence, awareness, treatment and control in national surveys from England, the USA and Canada, and correlation with stroke and ischaemic heart disease mortality: a cross-sectional study
}

\author{
Michel Joffres, ${ }^{1}$ Emanuela Falaschetti, ${ }^{2}$ Cathleen Gillespie, ${ }^{3}$ Cynthia Robitaille, ${ }^{4}$ \\ Fleetwood Loustalot, ${ }^{3}$ Neil Poulter, ${ }^{5}$ Finlay A McAlister, ${ }^{6}$ Helen Johansen, ${ }^{7}$ \\ Oliver Baclic, ${ }^{8}$ Norm Campbell ${ }^{9}$
}

To cite: Joffres M,

Falaschetti E, Gillespie C, et al. Hypertension prevalence, awareness, treatment and control in national surveys from England, the USA and Canada, and correlation with stroke and ischaemic heart disease mortality: a crosssectional study. BMJ Open 2013;3:e003423.

doi:10.1136/bmjopen-2013003423

- Prepublication history and additional material for this paper is available online. To view these files please visit the journal online (http://dx.doi.org/10.1136/ bmjopen-2013-003423).

Received 16 June 2013 Revised 26 July 2013 Accepted 29 July 2013

For numbered affiliations see end of article.

\section{Correspondance to} Dr Michel Joffres; mjoffres@sfu.ca

\section{ABSTRACT}

Objective: Comparison of recent national survey data on prevalence, awareness, treatment and control of hypertension in England, the USA and Canada, and correlation of these parameters with each country stroke and ischaemic heart disease (IHD) mortality. Design: Non-institutionalised population surveys. Setting and participants: England (2006 $n=6873)$, the USA (2007-2010 $n=10$ 003) and Canada (2007$2009 n=3485$ ) aged 20-79 years.

Outcomes: Stroke and IHD mortality rates were plotted against countries' specific prevalence data. Results: Mean systolic blood pressure (SBP) was higher in England than in the USA and Canada in all age-gender groups. Mean diastolic blood pressure (DBP) was similar in the three countries before age 50 and then fell more rapidly in the USA, being the lowest in the USA. Only $34 \%$ had a BP under $140 / 90 \mathrm{~mm} \mathrm{Hg}$ in England, compared with $50 \%$ in the USA and $66 \%$ in Canada. Prehypertension and stages 1 and 2 hypertension prevalence figures were the highest in England. Hypertension prevalence ( $\geq 140 \mathrm{~mm} \mathrm{Hg} \mathrm{SBP}$ and/or $\geq 90 \mathrm{~mm} \mathrm{Hg} \mathrm{DBP}$ ) was lower in Canada $(19.5 \%)$ than in the USA (29\%) and England (30\%). Hypertension awareness was higher in the USA (81\%) and Canada (83\%) than in England (65\%). England also had lower levels of hypertension treatment $(51 \%$; USA 74\%; Canada $80 \%)$ and control $(<140 / 90 \mathrm{~mm} \mathrm{Hg}$; $27 \%$; the USA 53\%; Canada 66\%). Canada had the lowest stroke and IHD mortality rates, England the highest and the rates were inversely related to the mean SBP in each country and strongly related to the blood pressure indicators, the strongest relationship being between low hypertension awareness and stroke mortality.

Conclusions: While the current prevention efforts in England should result in future-improved figures, especially at younger ages, these data still show important gaps in the management of hypertension in

\section{ARTICLE SUMMARY}

Article focus

- Comparison of hypertension prevalence, awareness, treatment and control in three National studies in England, the USA and Canada.

- Correlation with stroke and ischaemic heart disease mortality.

Key messages

- Important variation by country.

- Strong relationship between hypertension indicators and stroke mortality.

- Gaps in the management of hypertension.

Strengths and limitations of this study

- National population data.

- Detailed data on hypertension characteristics.

- Strong correlation with meaningful outcome, mortality.

- Data from England from 2006, but they provide an important basis for measuring progress (current data not yet available).

- Limited to three countries.

- Ecological correlation with mortality that excludes looking at confounders.

these countries, with consequences on stroke and IHD mortality.

\section{INTRODUCTION}

Increased blood pressure is the leading risk factor for premature death, stroke and heart disease worldwide. ${ }^{1}$ In the year 2000 , the world was estimated to have close to 1 billion people with hypertension and predicted an increase to 1.56 billion by $2025 .^{2}$ The global 
economic burden of increased blood pressure was estimated to consume US $\$ 370$ billion worldwide and $10 \%$ of healthcare expenditures. ${ }^{3}$ Usual blood pressure is strongly and directly related to vascular and overall mortality without evidence of a threshold down to at least $115 / 75 \mathrm{~mm} \mathrm{Hg},{ }^{4}$ with small changes in blood pressure resulting in substantial changes in vascular disease. ${ }^{5}$

On the basis of clinical and population research, increased blood pressure, hypertension and hypertension-related complications are largely preventable. Lifestyle changes can lower blood pressure and prevent hypertension while antihypertensive drug therapy can effectively reduce the cardiovascular events attributed to hypertension. ${ }^{1-6}$ Nevertheless, most people with hypertension worldwide are not effectively treated and controlled to the recommended blood pressure targets. $^{7}$ There are few national programmes to serve as models for prevention and control of hypertension and few countries have embarked on national hypertension prevention and control programmes. The USA blood pressure education programme was established in $1972^{8}$ while Canada (2000) and England (2004) have recent initiatives. ${ }^{9}{ }^{10}$ This manuscript compares recent data on the prevalence, awareness, treatment and control of hypertension in England, the USA and Canada and correlates these hypertension-related parameters in the three countries with mortality from stroke and ischaemic heart disease (IHD).

\section{METHODS}

Survey methods used in England, the USA and Canada are summarised in table 1. Detailed methodology for each survey is available elsewhere. ${ }^{11-13}$ Briefly, each survey is a representative sample of each country's noninstitutionalised population and uses standardised protocols and devices. While the England (2006) and Canada (2007-2009) surveys used automatic oscillometric devices, the USA (2007-2010) survey used mercury wall sphygmomanometer models. The number of blood pressure measurements available for analysis varied by count of blood pressure measures and survey protocols (table 1).

In these analyses, hypertension was defined as a mean systolic blood pressure $(\mathrm{SBP}) \geq 140 \mathrm{~mm} \mathrm{Hg}$ or a mean diastolic blood pressure (DBP) $\geq 90 \mathrm{~mm} \mathrm{Hg}$ or a respondent self-report of medication to lower blood pressure. Prehypertension (SBP 120-139 or DBP 80-89 $\mathrm{mm} \mathrm{Hg}$ ), stage 1 (SBP $140-159 \mathrm{~mm} \mathrm{Hg}$ or DBP

Table 1 Survey methods, by country

\begin{tabular}{|c|c|c|c|c|c|}
\hline Country & Years of survey & Sampling & $\mathbf{n}$ & $\begin{array}{l}\text { Age } \\
\text { range }\end{array}$ & Response rate \\
\hline England & 2006 & Multistage & 6873 & $20-79$ & $\begin{array}{l}68 \% \text { household response rate, } \\
88 \% \text { individual response rate in } \\
\text { co-operating households and } \\
66 \% \text { with nurse visit (examination } \\
\text { response rate). }\end{array}$ \\
\hline Canada & 2007-2009 & Multistage & 3485 & $20-79$ & $\begin{array}{l}\text { Household response rate }=70 \% \\
\text { Individual response rate to the } \\
\text { household questionnaire }=88 \% \\
\text { Examination response rate }=85 \%\end{array}$ \\
\hline USA & 2007-2010 & Multistage & 10003 & 20-79 & $\begin{array}{l}\text { Interview response rate }=79 \% \\
\text { Examination response rate }=76 \% \\
93 \% \text { of those examined had } \geq 2 \\
\text { blood pressure measurements }\end{array}$ \\
\hline Country & Blood pressure device & Technician & $\begin{array}{l}\text { No of blood } \\
\text { pressure } \\
\text { measures }\end{array}$ & \multicolumn{2}{|c|}{ Study protocol used } \\
\hline England & Omron HEM 907 & Nurse & 3 & \multicolumn{2}{|c|}{$\begin{array}{l}\text { Mean of second and third measures taken } \\
1 \text { min apart after } 5 \text { min rest }\end{array}$} \\
\hline Canada & Bp TRU BP-300* & $\begin{array}{l}\text { Health } \\
\text { measures } \\
\text { specialists }\end{array}$ & 6 & \multicolumn{2}{|c|}{$\begin{array}{l}\text { Average of last } 5 \text { of } 6 \text { measures taken } 1 \mathrm{~min} \\
\text { apart after a } 5 \mathrm{~min} \text { rest period }\end{array}$} \\
\hline USA & $\begin{array}{l}\text { Calibrated V-Lok cuff, Latex } \\
\text { Inflation Bulb, Air-Flo Control } \\
\text { Valve. Baumanometer calibrated } \\
\text { mercury wall model. }\end{array}$ & Physician & 3 & \multicolumn{2}{|c|}{$\begin{array}{l}\text { Mean of second and third measurements } \\
\text { taken } 30 \mathrm{~s} \text { apart after resting quietly in a } \\
\text { sitting position for } 5 \text { min } \dagger\end{array}$} \\
\hline
\end{tabular}


90-99 $\mathrm{mm} \mathrm{Hg}$ ) and stage 2 (SBP $\geq 160 \mathrm{~mm} \mathrm{Hg}$ or DBP $\geq 100 \mathrm{~mm} \mathrm{Hg}$ ) hypertension were defined according to the Seventh Report of the Joint National Committee on the Prevention, Detection, Evaluation and Treatment of High Blood Pressure (JNC 7) definitions. ${ }^{6}$

Prevalence, awareness, treatment, control and awareness of hypertension were defined using commonly recognised standards. Prevalence was defined as SBP $\geq 140$ or DBP $\geq 90$ or currently taking medication to lower their blood pressure. Awareness was defined by self-report and included, having been diagnosed as hypertensive by a doctor or nurse, excluding women diagnosed during pregnancy (England), medication to lower blood pressure in the past month or reported high blood pressure (Canada) or having been diagnosed as hypertensive by a doctor or nurse, excluding women diagnosed during pregnancy (USA). Treatment was defined as taking medication to lower blood pressure, as recorded by the nurse (England), or a self-report of taking medication to lower blood pressure (Canada and the USA). Treated and controlled was defined as taking medication to lower blood pressure and $\mathrm{SBP}<140$ and $\mathrm{DBP}<90 \mathrm{~mm} \mathrm{Hg}$; treated and uncontrolled a SBP $\geq 140$ or DBP $\geq 90 \mathrm{~mm} \mathrm{Hg}$ while on medication to lower blood pressure. Aware, yet not treated, was defined by self-report and included having been diagnosed as hypertensive by a doctor or nurse (England)/healthcare provider (Canada and the USA) and not taking medication to lower blood pressure.

Survey data were not age and sex standardised. They represent the current country-specific figures and therefore correspond more precisely to each country's crude mortality rates for stroke and IHD. All prevalence figures are weighted using survey weights to represent each country's population. SEs were computed taking into account each country's sampling methodology. ${ }^{11-13}$ To be comparable across the three surveys, the analysis was restricted to individuals aged 20-79 years and excluded pregnant women. The Canadian Health Measures Survey (CHMS) data analysis was performed using the SAS Enterprise Guide (V.4.1, SAS Institute Inc, Cary, North Carolina, USA, 2006). The Health Survey for England (HSE) data analysis was performed using SPSS V.19. The National Health and Nutrition Examination Survey (NHANES) data analysis was performed using SAS V.9.2 and SAS-Callable SUDAAN V.10 (RTI International)), to account for the complex sampling design.

The latest WHO country-specific mortality data available were from 2008 for Canada and the USA, ${ }^{14}$ and we used the 2006 data for England. ${ }^{15}$ Crude mortality rates per 100000 were obtained for men and women for stroke and ischaemic heart disease (IHD) and plotted against country-specific prevalence data for hypertension awareness, treatment and control.

\section{RESULTS}

The distribution of SBP and DBP by sex, age and country shows an increase in SBP with age and an increase, plateau and decrease in DBP with ageing (figure 1; see online supplementary appendix 1 table). SBP is higher in men than women in the younger age groups and becomes higher in women than men after age 60 years in Canada and age 70 years in England and the USA. The mean SBP is overall higher in England than in the USA and Canada in all age-gender groups. DBP is similar in the three countries before age 50 and then falls more rapidly in the USA while being lower overall in men and women from the USA.

The distribution of measured blood pressure (including treated individuals), by level, in table 2 reflects the findings in figure 1 . Only $34 \%$ of adults aged $20-79$ years would be classified as having a normal blood pressure $(<120 / 80 \mathrm{~mm} \mathrm{Hg})$ in England, compared with 50\% in the USA and $66 \%$ in Canada. Prehypertension and stages 1 and 2 hypertension prevalence figures are also much higher in England than in the USA and Canada.

The prevalence of hypertension, and awareness, treatment and control levels among those with hypertension
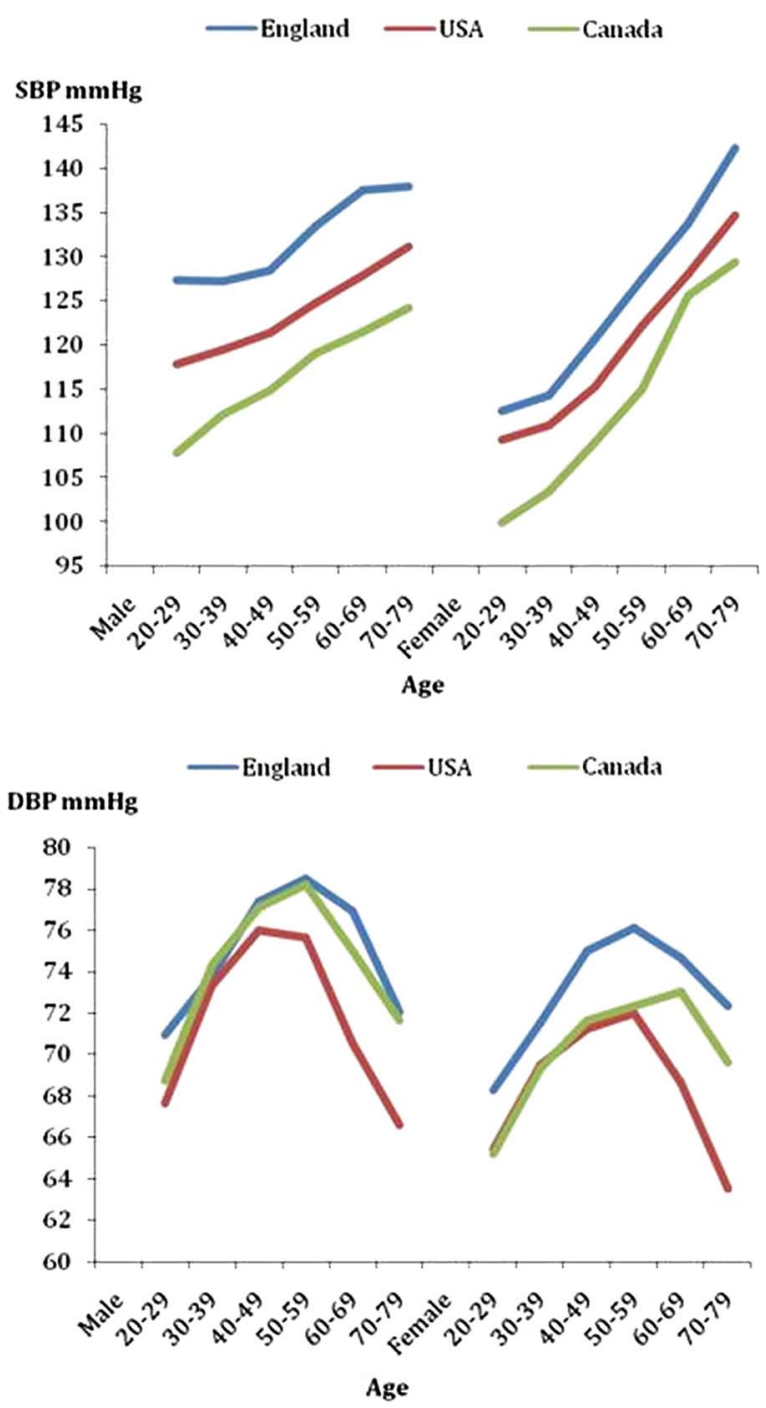

Figure 1 Distribution of systolic and diastolic blood pressure by country, age and sex. 
Table 2 Distribution of measured blood pressure by level, sex, age and country

\begin{tabular}{|c|c|c|c|c|c|c|c|c|c|c|c|c|c|}
\hline & \multirow[b]{2}{*}{ Total } & \multicolumn{3}{|c|}{ Normal } & \multicolumn{3}{|c|}{ Prehypertension } & \multicolumn{3}{|c|}{ Stage 1} & \multicolumn{3}{|c|}{ Stage 2} \\
\hline & & $\overline{\mathbf{n}}$ & Per cent & SE & $\bar{n}$ & Per cent & SE & $\bar{n}$ & Per cent & SE & $\bar{n}$ & Per cent & SE \\
\hline \multicolumn{14}{|l|}{ ENGLAND } \\
\hline All & 7382 & 2528 & 34.2 & 0.7 & 3242 & 43.9 & 0.7 & 1235 & 16.7 & 0.5 & 376 & 5.1 & 0.3 \\
\hline \multicolumn{14}{|l|}{ Sex } \\
\hline Males & 3555 & 761 & 21.4 & 0.8 & 1903 & 53.5 & 0.9 & 709 & 19.9 & 0.7 & 182 & 5.1 & 0.4 \\
\hline Females & 3826 & 1767 & 46.2 & 0.9 & 1339 & 35 & 0.9 & 526 & 13.7 & 0.6 & 195 & 5.1 & 0.4 \\
\hline \multicolumn{14}{|l|}{ Age } \\
\hline $20-39$ & 2618 & 1273 & 48.6 & 1.2 & 1115 & 42.6 & 1.1 & 210 & 8 & 0.6 & 20 & 0.8 & 0.2 \\
\hline $40-59$ & 2962 & 966 & 32.6 & 0.9 & 1360 & 45.9 & 0.9 & 482 & 16.3 & 0.7 & 155 & 5.2 & 0.4 \\
\hline $60-79$ & 1801 & 289 & 16.1 & 1 & 767 & 42.6 & 1.5 & 543 & 30.2 & 1.3 & 201 & 11.2 & 0.9 \\
\hline \multicolumn{14}{|l|}{ CANADA } \\
\hline All & 3485 & 2214 & 66.1 & 1.7 & 955 & 27.2 & 1.4 & 259 & 5.4 & 0.3 & 57 & $1.3^{*}$ & $0.2^{*}$ \\
\hline \multicolumn{14}{|l|}{ Sex } \\
\hline Males & 1649 & 951 & 60.6 & 2.4 & 538 & 32.9 & 2.2 & 140 & 5.9 & 0.5 & 20 & $0.7^{\star}$ & $0.2^{*}$ \\
\hline Females & 1836 & 1263 & 71.6 & 1.4 & 417 & 21.6 & 1.1 & 119 & 4.8 & 0.6 & 37 & $2.0^{\star}$ & $0.5^{\star}$ \\
\hline \multicolumn{14}{|l|}{ Age } \\
\hline $20-39$ & 1159 & 992 & 84.0 & 1.9 & 155 & 15.2 & 1.8 & $\dagger$ & $\dagger$ & $\dagger$ & $\dagger$ & $\dagger$ & $\dagger$ \\
\hline $40-59$ & 1231 & 785 & 63.4 & 3.3 & 351 & 30.2 & 2.8 & 81 & 5.3 & 0.7 & 14 & $1.1^{*}$ & $0.3^{*}$ \\
\hline $60-79$ & 1095 & 437 & 39.4 & 2.0 & 449 & 42.9 & 2.2 & 168 & 13.8 & 1.1 & 41 & $3.9^{*}$ & $1.0^{*}$ \\
\hline \multicolumn{14}{|l|}{ USA } \\
\hline All & 10003 & 4663 & 50.3 & 0.8 & 3615 & 36.0 & 0.7 & 1296 & 11.0 & 0.4 & 429 & 2.7 & 0.2 \\
\hline \multicolumn{14}{|l|}{ Sex } \\
\hline Males & 5033 & 1998 & 42.2 & 1.0 & 2109 & 42.7 & 1.0 & 713 & 12.2 & 0.6 & 213 & 2.8 & 0.3 \\
\hline Females & 4970 & 2665 & 58.3 & 1.0 & 1506 & 29.3 & 0.8 & 583 & 9.7 & 0.5 & 216 & 2.7 & 0.2 \\
\hline \multicolumn{14}{|l|}{ Age } \\
\hline 20-39 & 3394 & 2210 & 65.2 & 1.1 & 1007 & 29.7 & 1.1 & 148 & 4.4 & 0.4 & 29 & 0.7 & 0.1 \\
\hline $40-59$ & 3586 & 1608 & 46.5 & 1.3 & 1371 & 39.1 & 1.1 & 473 & 11.9 & 0.7 & 134 & 2.6 & 0.3 \\
\hline $60-79$ & 3023 & 845 & 30.8 & 1.3 & 1237 & 41.3 & 1.2 & 675 & 21.2 & 1.1 & 266 & 6.7 & 0.5 \\
\hline
\end{tabular}

are shown in table 3 . The prevalence of hypertension is lowest in Canada $(19.5 \%)$ and higher in the USA $(29 \%)$ and England (30\%). Hypertension awareness is close to $80 \%$ in the USA $(81 \%)$ and Canada $(83 \%)$ and lower in England $(65 \%)$. England also has lower levels of hypertension treatment (England 51\%; the USA 74\%; Canada $80 \%$ ) and control (England 27\%; the USA 53\%; Canada $66 \%)$. These patterns are similar in the different age and sex subgroups (table 3). Among individuals treated for hypertension (ie, taking medication to lower blood pressure), the proportion being controlled is lowest in England (53\%), compared with $71 \%$ in the USA and $82 \%$ in Canada.

The mean SBP and DBP are provided in online supplementary appendix 2 by the different prevalence categories of table 3. The data are consistent with those in the previous tables showing the highest SBP mean in England in all categories. For DBP also, England has higher means than the USA and Canada among all hypertensives and the aware and treated categories.

At the time when these surveys were being conducted, Canada had the lowest stroke and IHD mortality rates while England had the highest. The rates of both outcomes were inversely related to the mean SBP in each country (figure 2). We found a strong relationship between the selected blood pressure indicators and stroke and IHD mortality, the strongest relationship being between hypertension awareness and stroke mortality, especially in women (figure 3). Stroke rates were higher in women than men for any level of each of the BP indicators, and the opposite was true for IHD (figures 2 and 3).

\section{Discussion}

Although all the three countries evaluated have had substantive improvement in most hypertension treatment indicators over the past two decades, ${ }^{16-20}$ this study found marked differences in hypertension prevalence, awareness, treatment and control rates in England, the USA and Canada. Canada has the lowest prevalence of hypertension at $19 \%$ followed by England and the USA at about $30 \%$ each. A previous study based on earlier cycles of these surveys also found little difference in the prevalence of hypertension between England and the USA. $^{21}$ The main determinants of hypertension are known. These include poor dietary habits, excess sodium intake, physical inactivity, obesity, excess alcohol consumption, as well as age, gender, race and sociodemographic factors. The national differences in 
Table 3 Hypertension prevalence and percentage with hypertension, aware, treated, controlled, by sex, age group and country

\begin{tabular}{|c|c|c|c|c|c|c|c|c|c|c|c|c|}
\hline & \multicolumn{2}{|c|}{ Prevalence } & \multicolumn{2}{|l|}{ Aware } & \multicolumn{2}{|l|}{ Treated } & \multicolumn{2}{|c|}{$\begin{array}{l}\text { Treated and } \\
\text { controlled }\end{array}$} & \multicolumn{2}{|c|}{$\begin{array}{l}\text { Treated and } \\
\text { not controlled }\end{array}$} & \multicolumn{2}{|c|}{$\begin{array}{l}\text { Aware, not } \\
\text { treated }\end{array}$} \\
\hline & Per cent & $\mathrm{SE}$ & Per cent & SE & Per cent & SE & Per cent & SE & Per cent & SE & Per cent & SE \\
\hline \multicolumn{13}{|l|}{ ENGLAND } \\
\hline All & 30.0 & 0.7 & 65.3 & 1.2 & 51.3 & 1.2 & 27.3 & 1.1 & 23.9 & 0.9 & 14.1 & 0.8 \\
\hline \multicolumn{13}{|l|}{ Sex } \\
\hline Male & 32.9 & 0.9 & 60.6 & 1.5 & 45.1 & 1.6 & 23.9 & 1.4 & 21.2 & 1.2 & 15.5 & 1.1 \\
\hline Female & 27.3 & 0.8 & 70.7 & 1.5 & 58.2 & 1.6 & 31.1 & 1.6 & 27 & 1.4 & 12.5 & 1.1 \\
\hline \multicolumn{13}{|l|}{ Age } \\
\hline 20-39 & 9.3 & 0.7 & 35 & 3.1 & 10.6 & 2.1 & 5 & 1.4 & 5.6 & 1.7 & 24.4 & 2.9 \\
\hline $40-59$ & 27.9 & 0.8 & 59.3 & 1.7 & 40.8 & 1.8 & 23.1 & 1.5 & 17.7 & 1.2 & 18.5 & 1.3 \\
\hline $60-80$ & 63.7 & 1.3 & 76.1 & 1.6 & 67.4 & 1.7 & 35.1 & 1.8 & 32.3 & 1.6 & 8.7 & 0.9 \\
\hline \multicolumn{13}{|l|}{ CANADA } \\
\hline All & 19.5 & 0.6 & 83.4 & 1.8 & 79.9 & 2.0 & 65.8 & 2.0 & 14.0 & 2.0 & $3.5^{\star}$ & $0.9^{*}$ \\
\hline \multicolumn{13}{|l|}{ Sex } \\
\hline Male & 19.7 & 1.1 & 80.4 & 2.2 & 76.5 & 2.1 & 66.8 & 3.0 & $9.7^{*}$ & $2.0^{*}$ & $3.9^{*}$ & $0.9^{*}$ \\
\hline Female & 19.3 & 0.6 & 86.5 & 2.0 & 83.3 & 2.4 & 64.9 & 2.8 & $18.4^{*}$ & $3.2^{*}$ & $\dagger$ & $\dagger$ \\
\hline \multicolumn{13}{|l|}{ Age } \\
\hline 20-39 & $2.0^{*}$ & $0.6^{*}$ & 64.4 & 9.8 & $58.4^{*}$ & $10.3^{\star}$ & $56.8^{*}$ & $10.6^{*}$ & $\dagger$ & $\dagger$ & $\dagger$ & $\dagger$ \\
\hline $40-59$ & 18.4 & 1.5 & 80.4 & 2.7 & 73.4 & 3.7 & 65.4 & 3.8 & $8.0^{*}$ & $1.8^{*}$ & $7.0^{*}$ & $2.3^{*}$ \\
\hline $60-79$ & 53.2 & 2.4 & 86.7 & 1.8 & 85.7 & 2.1 & 66.8 & 1.8 & 19.0 & 2.6 & $\dagger$ & $\dagger$ \\
\hline \multicolumn{13}{|l|}{ USA } \\
\hline All & 29.1 & 0.8 & 81.1 & 1.0 & 74.0 & 1.1 & 52.8 & 1.0 & 21.2 & 0.7 & 7.0 & 0.7 \\
\hline \multicolumn{13}{|l|}{ Sex } \\
\hline Male & 29.4 & 1 & 77.7 & 1.4 & 69.1 & 1.5 & 48.7 & 1.6 & 20.3 & 1.1 & 8.6 & 1 \\
\hline Female & 28.8 & 0.9 & 84.6 & 1.2 & 79.1 & 1.4 & 57 & 1.5 & 22.1 & 1 & 5.5 & 0.7 \\
\hline \multicolumn{13}{|l|}{ Age } \\
\hline 20-39 & 7.7 & 0.6 & 61.1 & 4.6 & 47.2 & 4.0 & 35.0 & 3.6 & 12.2 & 2.4 & 13.9 & 2.5 \\
\hline $40-59$ & 31.1 & 1.2 & 82.4 & 1.4 & 73.1 & 1.8 & 53.5 & 1.7 & 19.6 & 1.3 & 9.4 & 1.0 \\
\hline 60-79 & 63.6 & 1.3 & 84.2 & 1.3 & 80.9 & 1.4 & 56.1 & 1.5 & 24.8 & 0.9 & 3.3 & 0.6 \\
\hline
\end{tabular}

Hypertension: systolic pressure $\geq 140$ or diastolic pressure $\geq 90$ or currently taking blood pressure-lowering medication.

Awareness, treatment and control were assessed among those with hypertension.

Aware: Self-report of having been diagnosed as hypertensive by a doctor or nurse, excluding women diagnosed during pregnancy (England);

Self-reported BP medication use in the past month or self-reported high-blood pressure (Canada); Self-report of having been diagnosed as hypertensive by a doctor or nurse, excluding women diagnosed during pregnancy (USA).

Treated: Taking medication to lower blood pressure recorded by the nurse (England); taking medication to lower blood pressure, self-report (Canada, USA).

Treated and controlled: taking medication to lower blood pressure and DBP $<90$ and SBP $<140 \mathrm{~mm} \mathrm{Hg}$.

Treated and uncontrolled: taking medication to lower blood pressure and DBP $>=90$ or SBP $>=140 \mathrm{~mm} \mathrm{Hg}$.

Aware, not treated: Self-reported of having been diagnosed as hypertensive by a doctor or nurse, not taking medication to lower blood

pressure (ENGLAND); Self-reported of having been told by a healthcare provider that they have high blood pressure, not taking medication to lower blood pressure (Canada); Self-reported of having been told by a healthcare provider that they have high blood pressure, not taking medication to lower blood pressure (USA).

Unaware: No self-report of having been diagnosed as hypertensive by a doctor or nurse (ENGLAND); no self-report of having been told that they have high-blood pressure and no self-report of BP medication use in the past month (Canada); no self-report of having been told that they have high-blood pressure (USA).

*Interpret with caution (coefficient of variation 16.6-33.3\%).

†Too unreliable to be reported (coefficient of variation greater than $33.3 \%$ ).

prevalence are most likely related to differences in the interaction between these determinants as well as differences in the clinical systems, community programmes and environmental and policy supports for hypertension prevention and management. Compared to the USA, Canada has a lower rate of obesity, but to our knowledge there has never been a comprehensive comparison of the determinants of blood pressure using appropriately adjusted data in these countries. A comprehensive comparison of the determinants of hypertension and the policies that fail to address adverse differences in the modifiable determinants would be an important next step. This is also important since these data show an important difference in the younger age groups between England, Canada and the USA. Since blood pressure tracks with age, ${ }^{22}$ efforts to influence the determinants of hypertension are essential to reduce hypertension prevalence in the older age groups. The recent decrease in childhood obesity in England ${ }^{23}$ should be followed by a reduction in blood pressure in the future surveys.

Our study has also found important differences in the awareness, treatment and control of hypertension in the 

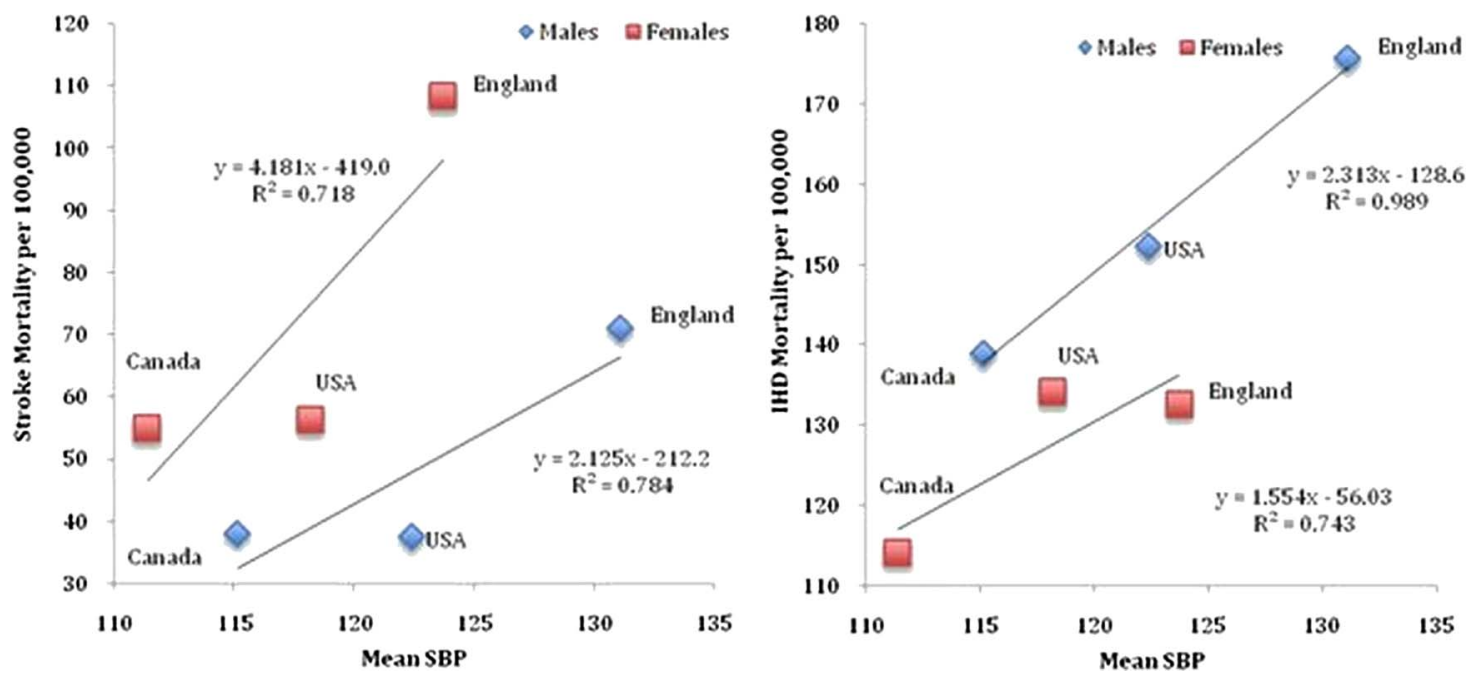

Figure 2 Stroke and ischaemic heart disease (IHD) mortality* by country mean SBP.

three countries. England, the USA and Canada all have developed differing approaches to improve hypertension treatment and control. In the USA, several diverse approaches have been taken. ${ }^{6}{ }^{24}$ Historically, the USA has had one of the world's highest rates of hypertension awareness, treatment and control and has also seen improvements in these indicators with intensified efforts $^{18}$; however, despite broad clinical and community efforts, over half of the adults with hypertension are uncontrolled based on the current guidelines. ${ }^{19}$ Recent national activities and recommendations are staged to positively impact hypertension estimates. ${ }^{25-29}$
Importantly, we also found national-level differences in mortality rates from stroke and IHD, which paralleled the differences in hypertension awareness, treatment and control between these three countries. Stroke and IHD mortality were strongly inversely correlated with mean SBP in each country.

Efforts in England have included episodic national hypertension recommendations developed by the British Hypertension Society (BHS-a non-governmental organisation of specialists and researchers) with the recommendations recently being developed by a governmental organisation in collaboration with the BHS. ${ }^{30}$
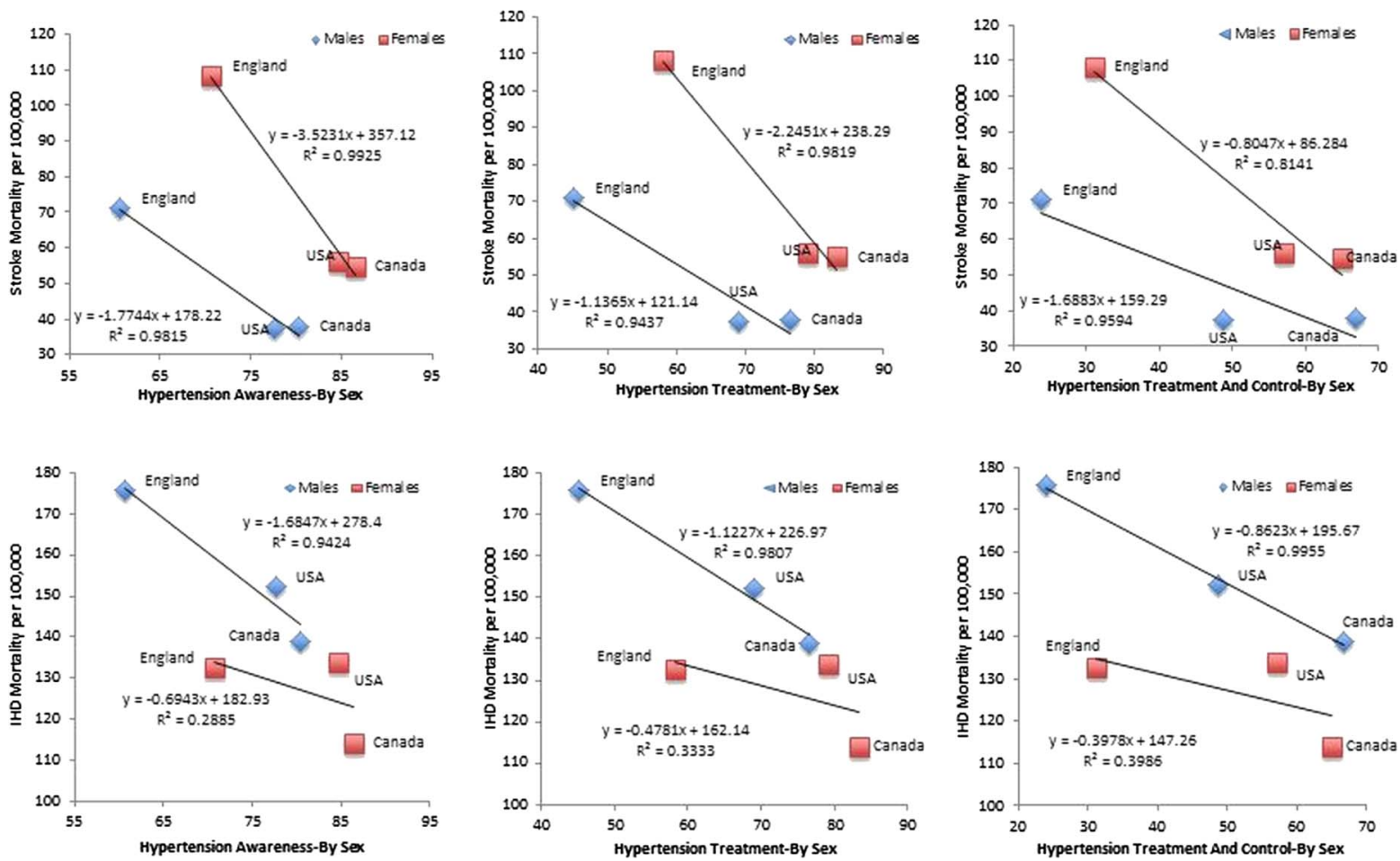

Figure 3 Stroke and IHD mortality by country prevalence of hypertension awareness, treatment and control. 
Implementation programmes have included an extensive public programme to educate people on the risks of salt for hypertension ${ }^{31}$ and also an extensive government programme to make bonus payments to general practitioners for achieving benchmarks for hypertension care $^{32}$-although the efficacy of payment for performance for improving hypertension control has been questioned. ${ }^{33}$

In 2000, Canada launched an annually updated hypertension recommendations programme (Canadian Hypertension Education Programme (CHEP)). ${ }^{9}$ In 2006 , the programme was assisted by an extensive initiative to inform the public about hypertension and the health risks and opportunities to reduce dietary salt. ${ }^{34}$ The introduction of CHEP in Canada is temporally related to improvements in management patterns and has also been temporally associated with reduced cardiovascular disease in Canada. ${ }^{35}$

It is difficult to assess how much the different national approaches to hypertension detection and management impact on the differences observed in our study. British Guidelines in place in $2006^{1036}$ and since ${ }^{30}$ do not recommend the routine use of antihypertensive treatment for those with a SBP >140 and/or DBP >90 mm Hg; rather, they do so only if such people have an estimated 10 year $\mathrm{CV}$ risk of $>20 \%$. Consequently, treatment rates and control rates might be expected to be lower in England than in the USA and Canada. Furthermore, in England, the National Institute for Health and Clinical Excellence's Quality and Outcomes Framework, which includes measures used in the calculation of provider reimbursement, included a higher blood pressure target $(<150 / 90)$ during the period of data used for these analyses. This will be lowered (to $<140 / 90$ ) in 2013/2014 to align with the national guidelines. In addition to the new National Institute for Health and Clinical Excellence guidelines, ${ }^{30}$ the national salt reduction programme in England would be expected to result in further reductions in the prevalence of hypertension and improvement in hypertension treatment indicators in recent and future years as Canadian and Finnish data suggest. ${ }^{37} 38$

There are several potential limitations to our current analyses. In addition to the low response rates and hence small numbers in some strata, each country uses different methodology to assess blood pressure and relatively small differences in blood pressure can impact the hypertension indicators. In particular, Canada has adopted the use of a fully automated blood pressure device that operates in the absence of an observer and averages the last five of six blood pressure readings. The Canadian method reduces the influence of the observer (white coat effect) on blood pressure and results in a slightly lower average blood pressure than a single auscultatory blood pressure reading. Nevertheless, using an algorithm to adjust the data in the Canadian survey ${ }^{39}$ to represent a single manual reading results in little change in the major hypertension indicators as the difference in methods at the therapeutic cut point of 140/
$90 \mathrm{~mm} \mathrm{Hg}$ is relatively small but might reduce the differences between the USA and Canada. The close relationship between stroke mortality and hypertension prevalence and hypertension indicators suggests that the blood pressure and hypertension differences seen in this study are real and biologically important. We acknowledge the limitation of using three points for our mortality graphs, which require a high level of correlation to be statistically significant.

We did not use age-adjusted or gender-adjusted data from the different countries. The lack of adjustment was intended so that the hypertension risk factors could be directly compared to stroke mortality for each country. In addition, in a separate analysis, comparison of age-adjusted data to a common standard population showed very little difference with the current figures. We were not able to obtain more recent common mortality data than 2008 for all countries. There is some overlap between the timing of the US and Canadian surveys, but the English survey was conducted more than 1 year earlier. Management of hypertension in England is quite likely to have improved since 2006. Increased blood pressure and hypertension represent major global threats to population health, with stroke and IHD being the most closely related adverse outcomes. ${ }^{4}$ Interventions to lower the average population blood pressure and interventions to identify and control blood pressure in those with hypertension are critical to prevent blood pressurerelated complications..$^{2-6}$ Nevertheless, the hypertension control rates are low even in developed countries and most countries do not have formal programmes to control hypertension. ${ }^{40}$ Further, population surveys indicate that approximately $29 \%$ of men and $25 \%$ of women have uncontrolled hypertension with increasing numbers of hypertension cases globally due to population growth and ageing. ${ }^{41}$ Hence, countries worldwide should consider introducing and evaluating coordinated programmes to improve the prevention, detection, awareness, treatment and control of hypertension, and our data suggest that the more assertive approach apparent in North America is associated with large benefits in terms of reduced cardiovascular mortality. A greater focus on prevention of high blood pressure in the younger age groups is also necessary.

\section{Author affiliations}

${ }^{1}$ Faculty of Health Sciences, Simon Fraser University, Burnaby, British Columbia, Canada

${ }^{2}$ Imperial Clinical Trial Unit, School of Public Health, Imperial College London, London, UK

${ }^{3}$ Division for Heart Disease and Stroke Prevention, Centers for Disease Control and Prevention, Atlanta, Georgia, USA

${ }^{4}$ Centre for Chronic Disease Prevention, Public Health Agency of Canada, Ottawa, Ontario, Canada

${ }^{5}$ International Centre for Circulatory Health, Imperial College London, London, UK

${ }^{6}$ Division of General Internal Medicine, University of Alberta Hospital, Edmonton, Alberta, Canada

${ }^{7}$ Department of Community Medicine and Epidemiology, University of Ottawa, Epidemiology \& Community Medicine, Ottawa, Ontario, Canada 
${ }^{8}$ Public Health Agency of Canada, Ottawa, Ontario, Canada

${ }^{9}$ Departments of Medicine, Community Health Sciences and of Physiology and Pharmacology, Libin Cardiovascular Institute, University of Calgary, Canada Libin Cardiovascular Institute of Alberta, University of Calgary, Calgary, Alberta, Canada

Contributors MJ, EF, CG and CR contributed to the data analysis, interpretation and writing. FL, NP, FAM, HJ, OB and NC contributed to the data interpretation and writing.

Funding Funding for NHANES comes from two primary sources: direct funding through the NCHS base budget and reimbursable funding from collaborating agencies; The Health Survey for England was funded by the National Health Centre; Health Canada and the Public Health Agency of Canada supported Statistics Canada in obtaining federal funding for the Canadian Health Measures Survey. Other sources of support: FAM is supported by an Alberta Innovates Health Solutions Senior Health Scholar Award and the University of Alberta/Capital Health Chair in Cardiovascular Outcomes Research. NC holds the Heart and Stroke Foundation of Canada CIHR Chair in Hypertension Prevention and Control. NP is grateful for support from the NIHR Biomedical Research funding scheme and the NIHR Senior Investigator Award. Funding of the original surveys.

Statement of independence of researchers from funders The findings and conclusions in this report are those of the authors and do not necessarily represent the official position of the Centers for Disease Control and Prevention, the Public Health Agency of Canada or the UK Department of Health.

Competing interests NP reports grants from Pfizer and from Hypertension Trust and personal fees from various Pharma companies, as well as from Servier, outside the submitted work. NC receives salary support for an HSFC CIHR Chair in Hypertension Prevention and Control.

Provenance and peer review Not commissioned; externally peer reviewed.

Data sharing statement All the authors had access to the original tables from the different studies, So no additional data are available.

Open Access This is an Open Access article distributed in accordance with the Creative Commons Attribution Non Commercial (CC BY-NC 3.0) license, which permits others to distribute, remix, adapt, build upon this work noncommercially, and license their derivative works on different terms, provided the original work is properly cited and the use is non-commercial. See: http:// creativecommons.org/licenses/by-nc/3.0/

\section{REFERENCES}

1. WHO. World Health Organization, World Health Statistics 2012. Geneva: World Health Organization, 2012. http://www.who.int/gho/ publications/world_health_statistics/2012/en/index.html (accessed Apr 2013).

2. Kearney PM, Whelton M, Reynolds K, et al. Global burden of hypertension: analysis of worldwide data. Lancet 2005;365:217-23.

3. Gaziano TA, Bitton A, Anand S, et al. The global cost of nonoptimal blood pressure. J Hypertens 2009;27:1472-7.

4. Lewington S, Clarke R, Qizilbash N, et al. Age-specific relevance of usual blood pressure to vascular mortality: a meta-analysis of individual data for one million adults in 61 prospective studies. Lancet 2002;360:1903-13.

5. Law MR, Morris JK, Wald NJ. Use of blood pressure lowering drugs in the prevention of cardiovascular disease: meta-analysis of 147 randomised trials in the context of expectations from prospective epidemiological studies. BMJ 2009;338:b1665.

6. Chobanian AV, Bakris GL, Black HR, et al. National Heart, Lung, and Blood Institute Joint National Committee on Prevention, Detection, Evaluation, and Treatment of High Blood Pressure; National High Blood Pressure Education Program Coordinating Committee. The Seventh Report of the Joint National Committee on Prevention, Detection, Evaluation, and Treatment of High Blood Pressure: the JNC 7 report. JAMA 2003;289:2560-72.

7. Kearney PM, Whelton M, Reynolds K, et al. Worldwide prevalence of hypertension: a systematic review. J Hypertens 2004;22:11-19.

8. National Heart Lung and Blood Institute. National High Blood Pressure Education Program. http://www.nhlbi.nih.gov/about/nhbpep/ index.htm (accessed Apr 2013).
9. McAlister FA. The Canadian Hypertension Education Program (CHEP) - a unique Canadian initiative. Can J Cardiol 2006;22:559-64.

10. National Institute for Health and Clinical Excellence. Hypertension: clinical management of primary hypertension in adults. Clinical guidelines, CG127-Issued: August 2011. http://guidance.nice.org. uk/CG127 (accessed Apr 2013).

11. CDC. National Health and Nutrition Examination Survey Data. Hyattsville, MD: US Department of Health and Human Services, CDC, 2010. http://www.cdc.gov/nchs/nhanes/about_nhanes.htm (accessed Apr 2013).

12. Craig R, Mindell J, eds. Health Survey for England 2006. London, UK: The Information Centre, 2008.

13. The Canadian Health Measures Survey: Rationale background and overview. http://www.statcan.gc.ca/pub/82-003-s/82003-s2007000-eng.htm (accessed Apr 2013).

14. Causes of Death 2008 Summary Tables, May 2011. Health statistics and informatics Department, World Health Organization, Geneva, Switzerland. http://www.who.int/evidence/bod (accessed Apr 2013)

15. Mortality Statistics Newport: Office for National Statistics. Deaths registered in 2006. Review of the Registrar General on deaths in England and Wales, 2006. http://www.ons.gov.uk/ons/rel/vsob1/ mortality-statistics-deaths-registered-in-england-and-walesseries-dr-/2006/data-tables-2006.zip (accessed Apr 2013).

16. Wilkins $\mathrm{K}$, Campbell NRC, Joffres MR, et al. Blood pressure in Canadian adults. Health Rep 2010;21:1-10.

17. Falaschetti $\mathrm{E}$, Chaudhury M, Mindell J, et al. Continued improvement in hypertension management in England: results from the health survey for England 2006. Hypertension 2009;53:480-6.

18. Egan BM, Zhao Y, Axon RN. US trends in prevalence, awareness, treatment, and control of hypertension, 1988-2008. JAMA 2010;303:2043-50.

19. Centers for Disease Control and Prevention. Vital signs: awareness and treatment of uncontrolled hypertension among adults-United States, 2003-2010 Morbidity and Mortality Weekly Report 2012;61:703-9.

20. McAlister FA, Wilkins $\mathrm{K}$, Joffres $\mathrm{M}$, et al. Changes in the rates of awareness, treatment and control of hypertension in Canada over the past two decades. CMAJ 2011;183:1007-13.

21. Martinson ML, Teitler JO, Reichman NE. Health across the lifespan in the United States and England. Am J Epidemiol 2011;173: 858-65.

22. Cheng S, Xanthakis V, Sullivan LM, et al. Blood pressure tracking over the adult life course: patterns and correlates in the Framingham heart study. Hypertension 2012;60:1393-9.

23. Lien N, Henriksen HB, Nymoen LL, et al. Availability of data assessing the prevalence and trends of overweight and obesity among European adolescents. Public Health Nutr 2010;13:1680-7.

24. United States Preventive Services Task Force. Recommendations. http://www.uspreventiveservicestaskforce.org/recommendations.htm (accessed Apr 2013)

25. Centers for Disease Control and Prevention. Million Hearts: strategies to reduce the prevalence of leading cardiovascular disease risk factors, United States, 2011. Morbidity and Mortality Weekly Report. 2011;60:1248-51.

26. Centers for Disease Control and Prevention. Sodium Reduction in Communities Program. http://www.cdc.gov/dhdsp/programs/sodium reduction.htm (accessed Apr 2013).

27. Centers for Disease Control and Prevention. Community Transformation Grant Program. http://www.cdc.gov/ communitytransformation/ (accessed Apr 2013).

28. US Department of Health and Human Services, US Department of Agriculture. Dietary Guidelines for Americans, 2010. 7th edn. Washington, DC, 2011.

29. Institute of Medicine. A population-based policy and systems change approach to prevent and control hypertension. Washington, DC: National Academy of Sciences, 2010.

30. National Institute for Health and Clinical Excellence. Hypertension: clinical management of primary hypertension in adults. Clinical guidelines, CG127. http://guidance.nice.org.uk/CG127 (accessed Apr 2013).

31. National Institute for Health and Clinical Excellence. Prevention of cardiovascular disease at the population level. Public health guidance, PH2; 2010. http://guidance.nice.org.uk/PH25 (accessed Apr 2013).

32. Doran T, Fullwood C, Gravelle $\mathrm{H}$, et al. Pay-for-performance programs in family practices in the United Kingdom. $N$ Engl J Med 2006;355:375-84.

33. Serumaga B, Ross-Degnan D, Avery AJ, et al. Effect of pay for performance on the management and outcomes of hypertension in the United Kingdom: interrupted time series study. BMJ 2011;342: d108. 
34. Campbell N, Young E, Drouin D, et al. A framework for discussion on how to improve prevention, management and control of hypertension in Canada. Can J Cardiol 2012;28:262-9.

35. McAlister FA, Feldman RD, Wyard K, et al. CHEP Outcomes Research Task Force. The impact of the Canadian Hypertension Education Programme in its first decade. Eur Heart J 2009;30:1434-9.

36. National Institute for Health and Clinical Excellence. Hypertension: management of hypertension in adults in primary care. Clinical guidelines, CG34; 2006. http://www.nice.org.uk/nicemedia/pdf/ CG034NICEguideline.pdf (accessed Apr 2013).

37. Joffres MR, Campbell NR, Manns B, et al. Estimate of the benefits of a population-based reduction in dietary sodium additives on hypertension and its related health care costs in Canada. Can $J$ Cardiol 2007;23:437-43.
38. Karppanen H, Mervaala E. Sodium intake and hypertension. Prog Cardiovasc Dis 2006;49:59-75.

39. Myers MG, Mclnnis NH, Fodor GJ, et al. Comparison between an automated and manual sphygmomanometer in a population survey. Am J Hypertens 2008;21:280-3.

40. Pereira M, Lunet N, Azevedo A, et al. Differences in prevalence, awareness, treatment and control of hypertension between developing and developed countries. J Hypertens 2009;27:963-75.

41. Danaei G, Finucane MM, Lin JK, et al. Global Burden of Metabolic Risk Factors of Chronic Diseases Collaborating Group (Blood Pressure). National, regional, and global trends in systolic blood pressure since 1980: systematic analysis of health examination surveys and epidemiological studies with 786 country-years and 5.4 million participants. Lancet 2011;377:568-77. 